Review Article

www.ijrap.net

\title{
OPEN DEFECATION IS A SERIOUS MENACE TO CHILD HEALTH: A COMPARATIVE SCENARIO BETWEEN INDIA AND TRIPURA
}

\author{
Nilimanka Das* \\ Regional Institute of Pharmaceutical Science \& Technology, Abhoynagar, Agartala, Tripura, India
}

Received on: 16/11/15 Revised on: 14/12/15 Accepted on: 29/12/15

\author{
* Corresponding author \\ E-mail: aandeehere@yahoo.co.in
}

DOI: $10.7897 / 2277-4343.07289$

\begin{abstract}
The progress of Millennium Development Goals (MDGs) is facing a great challenge from the issues like sanitation and hygiene. Open defecation is one worst facet of it and inflicts enormous harm to human health and largely lethal to the children under the age of five. Practicing open defecation pollutes ground water, contaminates agricultural produces and unveils the children to water borne diseases like diarrhea, dysentery, cholera, hepatitis A and typhoid resulting into impeded normal growth and cognitive development in them. India has topped list of the countries where 62 crore people defecate in public and $65 \%$ of which are women. Diarrhea is most prevalent form exhibiting higher rates of mortality of children under the age of five when compared to HIV/AIDS, malaria \& measles together. In India, it kills every year over 3 lakhs children under the age of five. When diarrhea does not kill, it empties the nutrients from the body and after repeated occurrence it results into stunted child growth. These children are endowed with more vulnerability to diseases and poor cognitive development. Unfortunately, $69 \%$ of Indian rural population doesn't have toilets and those having toilets, $40 \%$ defecate in open primarily due to inadequate water supply. According to UN, India had an economic loss of 53.8 billion USD in 2013 due to inadequate water supply and poor sanitation. To restore child health and to achieve sustainable economic and social development it is time worthy to curb open defecation.
\end{abstract}

Keywords: Open defecation, environmental enteropathy, stunting, wasting, Underweight, cognitive development, Tripura.

\section{INTRODUCTION}

Sanitation is a basic human right. It is very much essential for life, for health, for dignity, for empowerment and prosperity. Unfortunately, millions of people across the globe lack adequate sanitation and hygiene facilities. Poor sanitation and hygiene translates into devastating consequences on maternal health and globally a leading cause of child mortality under the age of five. Thanks to the constant efforts of United Nation which endowed the formulation of Millennium Development Goals (MDGs) concerned with maternal and child health. Open defecation is the worst facet of poor sanitation and inflicts enormous harm to maternal health and largely lethal to the children under the age of five. In India about 62 crore people defecate in public ${ }^{1}$ and $65 \%$ of which are women. Practicing open defecation pollutes water and burdens it with huge pool of harmful microbes. This condition exposes the children to the threat of water borne diseases like diarrhea, dysentery, cholera, hepatitis A and typhoid resulting into impeded normal growth and cognitive development in them ${ }^{2}$. Defecation in agricultural land contaminates the crops and after rain the water drains to the river and unites with ocean. This endangers the aquatic life like fish which sequentially expose the human again to the microbial diseases. Open defecation causes enormous harm to a pregnant women and her unborn baby. The baby thus born is very much prone to shunting and/or wasting. These endow the young population with poor health \& cognitive development. This results into weak economical workforce and may be a reason for serious impediment for India's development and prosperity.

Under this current scenario, the author has made an attempt to through light on certain issues concerned to MDGs and toilet facilities; impact of open defecation on maternal \& child health and the current scenario of toilet facilities available in Tripura when compared to India.

\section{MILLENNIUM DEVELOPMENT GOALS (MDG) ${ }^{3}$}

Toilet in Poverty and Hunger Eradication (MDG 1)

Investments in sanitation facilities contribute country's economic productivity. Correct utilization of toilets would enhance contamination free agricultural produces which will provide revenues from sale of such products and greatly helps in hunger eradication. Advanced sanitation facilities reduce economic burden on health system. People affected by diarrheal disease require health care support which is expensive for the patient (transport, medicine, time-loss) and the government (medical consultation, treatment, medication). Tourism always helps to earn foreign currency and it is very much essential for any developing country like India. Poor sanitation badly affects this sector and increase economic burden.

\section{Toilet and Education (MDG 2)}

School attendance and retention is deeply related to the availability of sanitation facilities. This facility also increases employment and quality of life. Improved sanitation has positive impact on education opportunities for young girls who are vulnerable to lack of privacy and cleanliness during their period.

Toilet and Gender Equality (MDG 3)

Poor sanitation affects women more than men. Many a time women need to travel to a longer distance to use the toilet facility or to defecate in open. Hence they are more susceptible to sexual harassment and violence. This problem is severe in densely populated area to find privacy. This compels them to refrain from urinating and defecating for many hours which in turn cause urinary tract infections. 
Toilet and Reduction of Child Mortality (MDG4)

Diarrheal disease caused by inadequate sanitation lead to vitamin and mineral deficiency. This makes them susceptible to any disease and vulnerable to high morbidity, malnutrition, stunting and mortality. Sustained exposure to excreta related pathogens including helminthes in early life limits cognitive development and lowers immunity.

\section{Toilet and Environment (MDG 7)}

From environmental perspective, improving sanitation would contribute to the mitigation of urgent climatic changes such as water stress, unexpected natural disasters, environmental degradation and excessive resource depletion.

\section{IMPACT OF OPEN DEFECATION ON MATERNAL AND CHILD HEALTH}

\section{Maternal Health}

Open defecation causes enormous harm to a pregnant women and her unborn baby. The new born may suffer from congenital microbial disease which in the long run may translate into shunted and/or wasted growth. These dire consequences seriously impede physical and cognitive development among the survived children. These children are always vulnerable to morbidity \& mortality and ultimately reduces nation's workforce.

\section{Child Health \& Environmental Enteropathy}

Fecal ingestion causes enteric infection followed by intestinal inflammation ${ }^{4}$ in young children. This inflammation increases intestinal permeability and allows bacterial translocation. This activates the innate and acquired immune system which translates into environmental enteropathy ${ }^{5}$. Enteropathy is characterized by chronic villous atrophy, crypt hyperplasia and inflammatory cell filtrate. Chronic villous atrophy is a condition characterized by the erosion of intestinal villi's leaving a flat surface. Villi's are responsible for absorption of nutrients from food. As the villi's are completely absent in villous atrophy, absorption of nutrients are impeded resulting into malnourished children. Normally the ratio of villi to crypt length is $3-5: 1$. But in crypt hyperplasia, crypts are enlarged and the length of villi is diminished resulting altered villi crypt. Chronic villous atrophy and crypt hyperplasia leads to chronic inflammatory infiltrate in lamina propria. This condition is more common in children than adults $(56 \%$ vs. $28 \%)$. This pathology dictates poor absorption of nutrients, vitamins and oral vaccines leading to devastating consequences like increased child mortality, reduced cognitive development and reduced adult economic productivity (Figure $1)$.

\section{IMPACT OF OPEN DEFECATION: STUNTED, WASTED AND UNDERWEIGHT CHILDREN}

Open defecation has direct relation with nutritional deficiencies and more prevalent in underprivileged. Scheduled Tribe (ST) and Scheduled Caste (SC) young population are more stunted, wasted and underweight when compared with other children of the society. Stunting is determined by comparing a person's height to the standard height of a healthy population of the same age and gender. A child is stunted if his/her height is more than two standard deviations below the WHO standard. Wasting is considered when his/her weight is more than two standard deviations below from the median weight for height of reference population. Children from Other Backward Classes (OBC) fall in the middle of the scale on all three measures of nutritional status. Though children from other section are less stunted, wasted and underweight, yet they also suffer from higher levels of under-nutrition in comparison to a normal healthy population (Figure 2).

Stunting has long-term negative impact on health. The risks associated with stunting begin in the womb and continue throughout life. Babies born to underweight or stunted women are likely to be underweight or stunted. In this way the feature passes from one generation to the next ${ }^{6}$. Woman less than 145 $\mathrm{cm}$ or $4^{\prime} 7^{\prime \prime}$ in height is considered to be stunted. Her physical status offers increased risk to the survival, health and development of her newborn. There is increased risk of disparity in size between the baby's head and mother's pelvis. Due to this disproportion, short mothers are less likely to have successful spontaneous vaginal delivery ${ }^{7,8}$ which again increases the risk of maternal mortality and short \& long term disability.

Stunted growth is an impediment to the education and economic advancement. Stunting is strongly linked to the ability to learn and cognitive development. Stunting results from restricted nutrient supply and/or frequent infection turn into short stature of the child. This also results in structural and functional damage of brain leading to delayed development of cognitive functions as well as permanent cognitive impairments ${ }^{9}$.

\section{CURRENT SCENARIO OF OPEN DEFECATION IN INDIA AND TRIPURA ${ }^{10}$}

In India $67 \%$ rural and $13 \%$ urban population defecate in open (Figure 3).

Open defecation is associated with significant negative consequences. The faces, source of deadly germs are liberated in the open environment and harm the rich and poor in a similar manner and also those who uses latrine. So emphasis must be given to build more numbers of toilets with adequate water facility and combined with technologies that don't negatively impact ground water quality.

A comparative scenario of Indian rural and urban households with no latrine facility is shown in Figure 4. Figure 5 is another comparative representation of Indian household with Tripura in case of latrine availability status in 2001 \& 2011. 


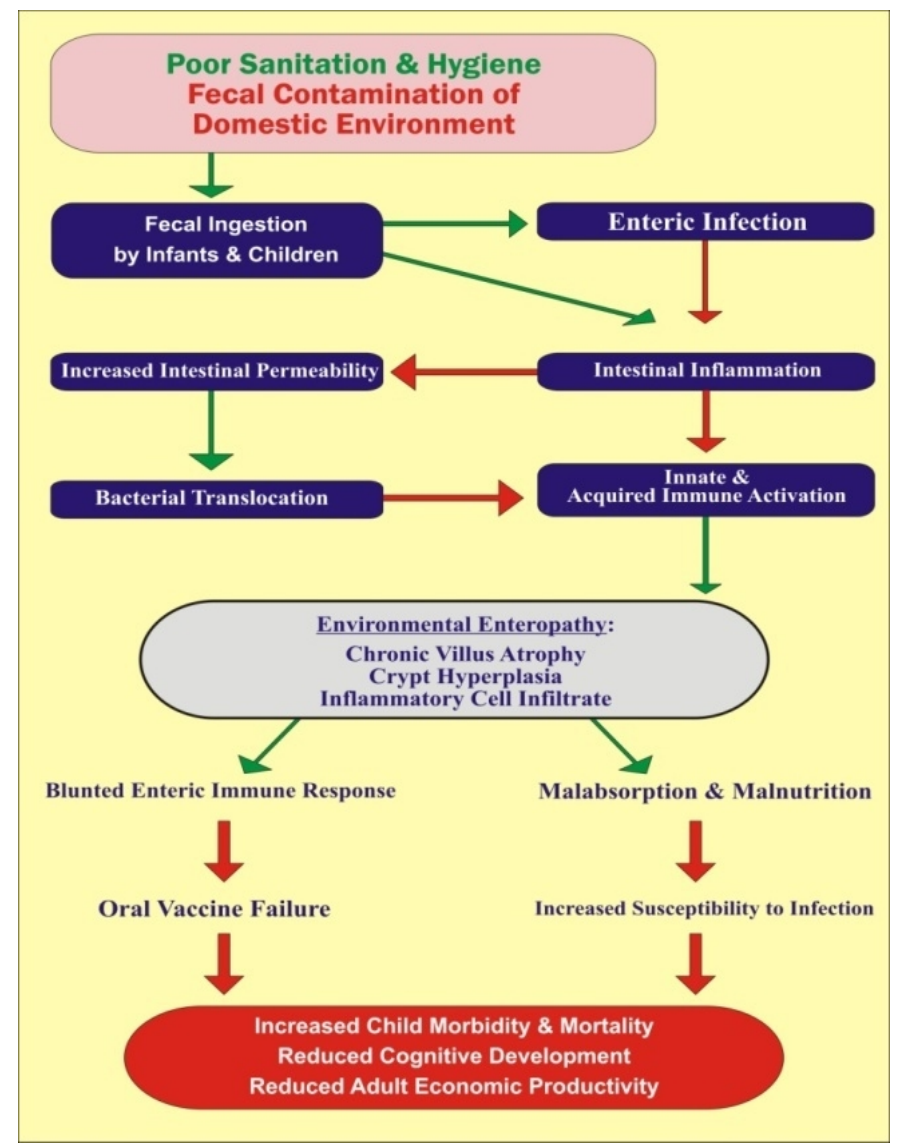

Figure 1: Schematic representation of Environmental Enteropathy and its consequences ${ }^{5}$.

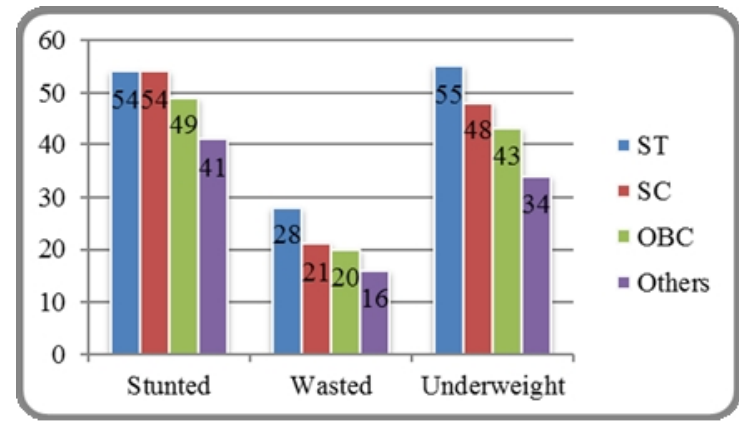

Figure 2: Stunting, Wasting and Underweight among children under the age of five of different caste and class.

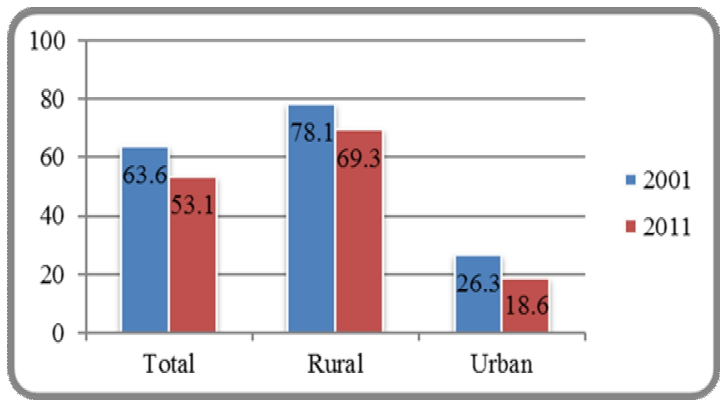

Figure 4: Percentage of Indian households having no latrine (2001 \& 2011)

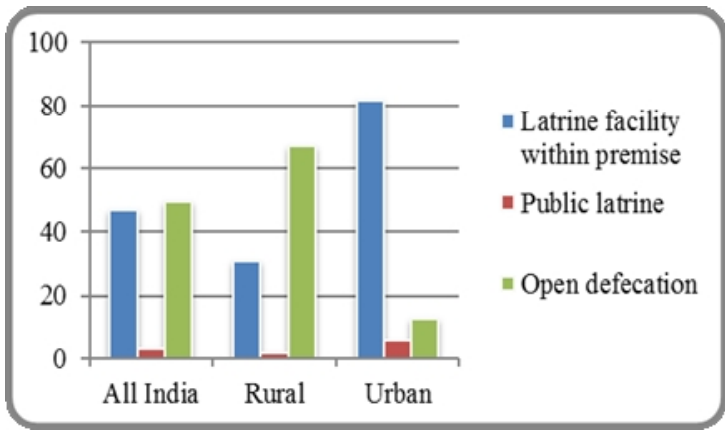

Figure 3: Households with different types of latrine facility (\%).

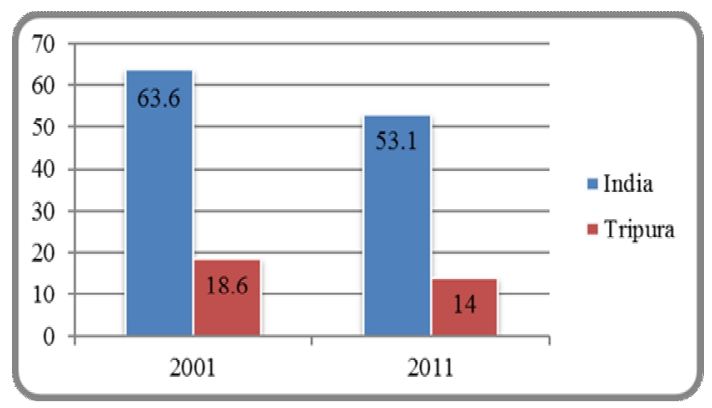

Figure 5: Percentage of households having no latrine: India \& Tripura (2001 \& 2011) 


\section{CONCLUSION}

From the information's available, it is very much clear that open defecation is a serious menace and must be reviewed strictly to restore maternal and child health to ensure sustainable economic and social development of our country. It is time worthy to invest in toilets and to vigil that every sphere of life is being benefitted by its use.

\section{ACKNOWLEDGEMENT}

The author is grateful for the support extended by Regional Institute of Pharmaceutical Science \& Technology, Agartala, Tripura, India to carry out this piece of work.

\section{REFERENCES}

1. Singh P, Chavan P, Mathur D. Open Defecation: This is also your business. Policy brief series: No. 20; 2013; AugustSeptember: 1-8.

2. Ghosh A, Cairncross S. The uneven progress of sanitation in India. J water Sanit Hyg Dev 2014; 4 (1): 15-22.

3. Roma E, Pugh I. Toilets for Health. A Report by the London School of Hygiene and Tropical Medicine in Collaboration with Domestos 2012; November: 1-28.

4. Sajeeth G, Durga AV, Bai AJ. Open defecation- A threat to protected water source of Gajapatinagaram Mandal of
Vizianagaram district, Andhra Pradesh, India. Int J Res Ayurveda Pharm 2011; 2(2): 597-601.

5. Korpe PS, Petri Jr. WA. Environmental enteropathy: critical implications of a poorly understood condition. Trends Mol Med 2012; 18 (6): 328-336.

6. World Bank. Repositioning nutrition as central to development: a strategy for large scale action. Washington DC: The International Bank for Reconstruction and Development/The World Bank; 2006.

7. Kwawukume EY, Ghosh TS, Wilson JB. Maternal height as a predictor of vaginal delivery. Int J Gynaecol Obstet 1993; 41 (1): 27-30.

8. Merchant KM, Villar J, Kestler E. Maternal height and newborn size relative to risk of intrapartum caesarean delivery and perinatal distress. Bjog-Int J Obstet Gy 2001; 108 (7): 689-96.

9. Kar B, Rao S, Chandramouli B. Cognitive development in children with chronic protein energy malnutrition. Behav Brain Funct 2008; 4(1):31.

10. Availability and type of latrine facility: 2001- 2011. Census of India 2011; 1-2.

\section{Cite this article as:}

Nilimanka Das. Open defecation is a serious menace to child health: A comparative scenario between India and Tripura. Int. J. Res. Ayurveda Pharm. Mar - Apr 2016;7(Suppl 2):210-213 http://dx.doi.org/10.7897/2277-4343.07289

Disclaimer: IJRAP is solely owned by Moksha Publishing House - A non-profit publishing house, dedicated to publish quality research, while every effort has been taken to verify the accuracy of the content published in our Journal. IJRAP cannot accept any responsibility or liability for the site content and articles published. The views expressed in articles by our contributing authors are not necessarily those of IJRAP editor or editorial board members. 